OPEN ACCESS

Edited by:

David Nikolic-Paterson,

Monash University, Australia

Reviewed by:

Patrick Ming-Kuen Tang,

The Chinese University of Hong Kong,

China

Vladimir T. Todorov

Technische Universität Dresden,

Germany

*Correspondence:

Yiming Zhou

zhouym35@mail.sysu.edu.cn

Specialty section

This article was submitted to Renal and Epithelial Physiology,

a section of the journal

Frontiers in Physiology

Received: 03 August 2021 Accepted: 20 September 2021

Published: 13 October 2021

Citation:

Zeng $H$, Yang $X$, Luo $S$ and Zhou Y (2021) The Advances of Single-Cell RNA-Seq in Kidney

Immunology.

Front. Physiol. 12:752679. doi: 10.3389/fphys.2021.752679

\section{The Advances of Single-Cell RNA-Seq in Kidney Immunology}

\author{
Honghui Zeng 1,2, Xiaoqiang Yang 1,2, Siweier Luo ${ }^{1,2}$ and Yiming Zhou ${ }^{1,2 *}$ \\ ${ }^{1}$ Guangdong Provincial Key Laboratory of Malignant Tumor Epigenetics and Gene Regulation, Guangdong-Hong Kong Joint \\ Laboratory for RNA Medicine, Sun Yat-sen Memorial Hospital, Sun Yat-sen University, Guangzhou, China, ${ }^{2}$ Medical \\ Research Center, Sun Yat-sen Memorial Hospital, Sun Yat-sen University, Guangzhou, China
}

Kidney diseases are highly prevalent and treatment is costly. Immune cells play important roles in kidney diseases; however, it has been challenging to investigate the contribution of each cell type in kidney pathophysiology. Recently, the development of single-cell sequencing technology has allowed the extensive study of immune cells in blood, secondary lymphoid tissues, kidney biopsy and urine samples, helping researchers generate a comprehensive immune cell atlas for various kidney diseases. Here, we discuss several recent studies using scRNA-seq technology to explore the immune-related kidney diseases, including lupus nephritis, diabetic kidney disease, IgA nephropathy, and anti-neutrophil cytoplasmic antibody-associated glomerulonephritis. Application of scRNA-seq successfully defined the transcriptome profiles of resident and infiltrating immune cells, as well as the intracellular communication networks between immune and adjacent cells. In addition, the discovery of similar immune cells in blood and urine suggests the possibility of examining kidney immunity without biopsy. In conclusion, these immune cell atlases will increase our understanding of kidney immunology and contribute to novel therapeutics for patients with kidney diseases.

Keywords: kidney, immune system, single-cell RNA sequencing, lupus nephritis, diabetic kidney disease, IgA nephropathy, anti-neutrophil cytoplasmic antibody-associated glomerulonephritis

\section{BACKGROUND}

The kidneys are vital organs serving critical functions in the human body, including clearance of waste from blood, maintenance of the salt/water balance, and regulation of blood pressure. In addition to these functions, the kidneys also maintain the homeostasis of the immune system through filtration and excretion of bacterial toxins, circulating cytokines, and inflammatory molecules (Kurts et al., 2013; Donnan et al., 2021). Although considerable progress has been achieved in elucidating the contribution of immune cells in kidney diseases and in translating these results from the bench to the bedside, determining how these immune cells orchestrate kidney immunology in health and disease remains a challenge due to the relatively small number of immune cells and the highly complex cell composition of kidneys. Hence, our understanding of kidney immunology in humans remains incomplete.

In health, the major kidney resident immune cells are dendritic cells (DCs) and macrophages (Cao et al., 2011; Kurts et al., 2013, 2020). A small number of lymphocytes are also present in healthy kidneys (Turner et al., 2018). Therefore, the kidneys, similar to the spleen, can maintain the peripheral tolerance through the kidney resident antigen-presenting cells (APCs). This becomes more obvious in end-stage renal disease (ESRD), where both kidney function and the immune system are severely compromised. Retention of excessive toxins and cytokines in ESRD activates innate immune cells and increases the production of cytokines and proinflammatory molecules, 
which further causes kidney damage (Betjes, 2013). Kidneyresident DCs, derived from common DC precursors (CDPs) and monocytes, are located in the tubulointerstitium and absent in the glomeruli (Teteris et al., 2011). Resident DCs in the kidney appear to be crucial for maintaining peripheral tolerance via direct interaction with filtered antigens in the tubular lumen regions and for presenting these antigens to $\mathrm{T}$ cells in lymph nodes, which may be more efficient in kidneys than in other organs. In ischemia-reperfusion (IR) and unilateral ureter obstruction (UUO) mouse models, resident DCs promoted kidney injury by producing proinflammatory cytokines. In contrast to DCs, kidney-resident macrophages are scattered in the renal cortex and infiltrate into the tubulointerstitium during tissue damage. Some evidence suggests that kidney-resident macrophages play protective roles during acute and chronic kidney diseases. Studies found that the lack of resident kidney CD45 ${ }^{+}$Ly6GF4/80 ${ }^{\text {high }}$ CD $11 b^{\text {int }}$ macrophages, which express an inhibitory immune checkpoint molecule, V-domain Ig suppressor of $\mathrm{T}$ cell activation (VISTA), delays tissue repair in several animal models (Park et al., 2020). CD11b ${ }^{\text {int }}$ F4/80 bright kidney resident macrophages were found to be protective in the ischemic kidney by promoting proangiogenic environments (Puranik et al., 2018). In contrast, other studies argue that activation of macrophages aggravates kidney injury through the production of proinflammatory cytokines (Yang et al., 1998; Isbel et al., 2001; Eardley et al., 2008). Thus, kidney-resident macrophages seem to have diverse effects depending on cell identity, the kidney injury type and the disease stage.

On one hand, kidneys can be the direct target of the immune system, by which lymphocytes and/or antibodies interact with kidney cells and lead to kidney damage. Tubulointerstitium DCs might capture glomerular antigens, which in turn induce infiltrating $\mathrm{T}$ cells to produce proinflammatory cytokines. Infiltrating monocytes also contribute to local inflammation and tissue injury, which have been shown to cause tubular atrophy and interstitial scarring. On the other hand, kidneys can be an indirect victim of immune system dysregulation, such as the immune complexes deposition in glomeruli that promote local inflammation. Immune complexes can be a result of either an immune response to infection or a systemic autoimmune disease condition (e.g., SLE). In both cases, activation of innate and adaptive immune cells, as well as the complement system, play important roles in various kidney diseases.

Although a number of previous studies have confirmed the contribution of immune cells in kidney diseases (Kurts et al., 2013; Donnan et al., 2021), each of these studies focus on fewer than three immune cell populations. To date, therefore, our knowledge and understanding of kidney immunology as a whole is still incomplete. Here, we discuss the recent progress and findings in kidney diseases uncovered by scRNAseq technology. We briefly introduce the general principles and current methodologies of scRNA-seq as well as the experimental design for basic and clinical research related to the kidney field. We then discuss recent findings focusing on several immune-related kidney diseases, including LN, DKD, IgAN, and ANCA-GN, highlighting the changes in immune cell populations and the possible immune mechanisms revealed by scRNA-seq technology. Finally, we discuss how the generation of immune cell atlases might help transform these results into immunological therapies in the future.

\section{COMPARISON OF SINGLE-CELL RNA-SEQ METHODS}

scRNA-seq technology has been rapidly developed in recent decades (Figure 1; Tang et al., 2009; Islam et al., 2011; Ramskold et al., 2012; Macosko et al., 2015; Gierahn et al., 2017), enabling the characterization of transcriptome profiles in heterogeneous cell populations at the single-cell resolution (Wagner et al., 2016). To date, several scRNA-seq methods are commercially available; each with distinct strengths and limitations with respect to experiment throughput, detection sensitivity, gene coverage, and cost per cell (Table 1). General workflow of scRNA-seq includes single-cell preparation, cell capture and lysis, mRNA capture and reverse transcription, cDNA amplification, library construction, next-generation sequencing, and computational analysis. According to the sequencing length, single-cell RNAseq can be divided into full-length, $3^{\prime}$ and $5^{\prime}$ end sequencing methods. Full-length sequencing captures the whole mRNA sequences and has a deeper sequencing depth, which make it very useful in studying genes related to alternative splicing or at low levels. Both $3^{\prime}$ and $5^{\prime}$ end sequencing has higher experimental throughput and lower cost per cell. Currently, $3^{\prime}$ end sequencing is more frequently used for whole transcriptomic assays, while the $5^{\prime}$ end is used to detect the clonal diversity of $\mathrm{T}$ and $\mathrm{B}$ cells trough TCR or BCR $\mathrm{V}(\mathrm{D}) \mathrm{J}$ sequencing (Papalexi and Satija, 2018). With the rapid development and commercialization of these scRNA-seq methods, an increasing number of open-source computational tools, from data quality control, batch effect correction, dimension reduction analysis, to data visualization, have been developed, which further made scRNA-seq technology applicable to most researchers. To date, several scRNA-seq methods have been used to investigate more than 10,000 cells simultaneously, allowing us to identify both rare and novel cell populations, investigate the transcriptomic changes in each cell and analyze the intercellular communication networks. As mentioned above, single-cell preparation is the first step of all scRNA-seq technologies which require fresh tissue samples and successful dissociation of tissue to generate good quality data and cells should be smaller than the droplets or microwells. To overcome these technical barriers, researchers developed the single-nucleus RNA-sequencing (snRNA-seq) method (Krishnaswami et al., 2016; Lacar et al., 2016; Habib et al., 2017), where nuclear, not cytoplasmic RNA is sequenced. Although the RNA-splicing information is lost and the detection sensitivity is reduced because of the increased level of pre-mRNA, snRNA-seq is particularly helpful in studying the dissociationresistant or frozen samples, and cells with diameters over 50 $\mu \mathrm{m}$. Therefore, researchers should carefully select scRNA-seq methods for their studies based on the tissue origin, sample size, sample storage method, and target cell abundance. It is highly recommended that target cells should be enriched by FACS when their population is less than $5 \%$ of the total. 


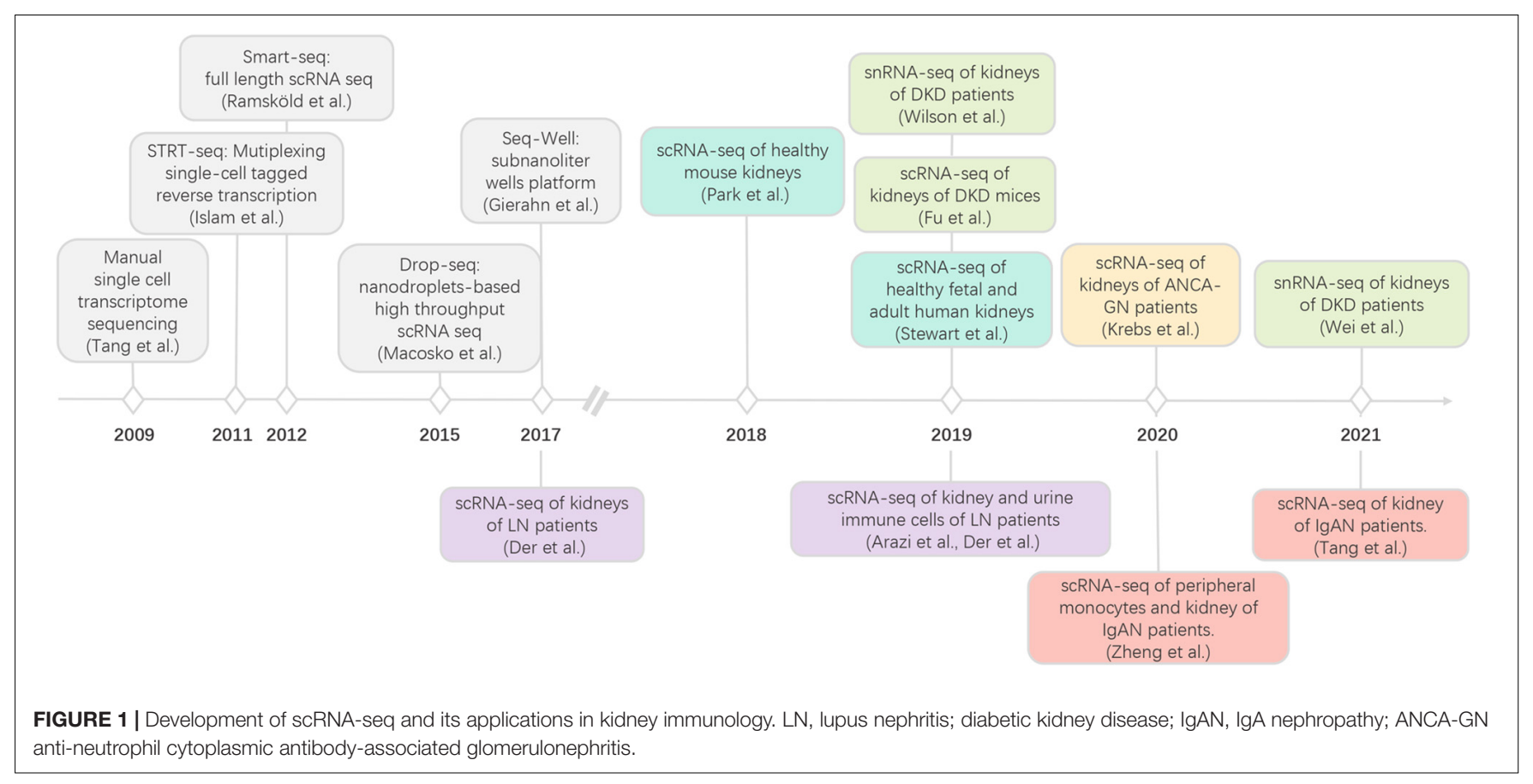

TABLE 1 | List of scRNA-seq methods.

\begin{tabular}{|c|c|c|c|c|c|}
\hline & SMART-seq/C1 & SMART-seq2 & CEL-seq2/C1 & $\begin{array}{l}10 \times \text { Genomics } \\
\text { chromium }\end{array}$ & BD rhapsody \\
\hline $\begin{array}{l}\text { Single cell preparation and } \\
\text { capture }\end{array}$ & $\begin{array}{l}\text { Fluidigm C1 } \\
\text { platform }\end{array}$ & FACS & C1 platform & $\begin{array}{l}10 \times \text { Genomics } \\
\text { chromium platform }\end{array}$ & $\begin{array}{l}\text { BD rhapsody } \\
\text { platform }\end{array}$ \\
\hline Sample preparation & Complicated & Complicated & Complicated & Easy & Easy \\
\hline Quality check & Microscope & No & Microscope & No & $\begin{array}{l}\text { BD rhapsody } \\
\text { platform }\end{array}$ \\
\hline UMI-based & No & No & Yes & Yes & Yes \\
\hline cDNA coverage & Full-length & Full-length & 3' counting & $5^{\prime}$ or $3^{\prime}$ counting & $5^{\prime}$ or $3^{\prime}$ counting \\
\hline Amplification method & TS-based PCR & TS-based PCR & In vitro transcription & TS-based PCR & TS-based PCR \\
\hline Sample multiplexing & No & No & No & Yes & Yes \\
\hline Cell number limitation & $\begin{array}{l}5-10,10-17, \text { or } \\
17-25 \mu \mathrm{m}\end{array}$ & Less than $50 \mu \mathrm{m}$ & Less than $50 \mu \mathrm{m}$ & Less than $50 \mu \mathrm{m}$ & Less than $50 \mu \mathrm{m}$ \\
\hline $\begin{array}{l}\text { Required cell numbers per } \\
\text { run }\end{array}$ & $>10,000$ & No limitation & $>10,000$ & $>10,000$ & $>20,000$ \\
\hline Long term storage & No & Yes & No & No & Yes \\
\hline Throughput capability & $\begin{array}{l}\text { Limited by number } \\
\text { of machines }\end{array}$ & $\begin{array}{l}\text { Limited by operator } \\
\text { efficiency }\end{array}$ & $\begin{array}{l}\text { Limited by number } \\
\text { of machines }\end{array}$ & $\begin{array}{l}\text { Up to } 8 \text { samples } \\
\text { per chip }\end{array}$ & $\begin{array}{l}\text { Limited by operator } \\
\text { efficiency }\end{array}$ \\
\hline Cost & High & High & Medium & Low & Low \\
\hline
\end{tabular}

A study showed that snRNA-seq performed well on inflamed fibrotic tissue and could capture more cell types including glomerular podocytes, mesangial cells, endothelial cells, and juxtaglomerular cells with reduced dissociation-induced bias and transcriptional stress responses compared to scRNA-seq (Wu et al., 2019).

In addition to aforementioned scRNA-seq methods, which provide robust information of different cell populations but lose the spatial characteristics of samples, high-throughput spatial transcriptomics techniques were developed and most of them recorded the spatial information by labeling mRNA transcripts with location barcodes. Following detachment and deep sequencing, spatial transcriptomics techniques align transcripts to their capture spots of origin based on their location barcode (Longo et al., 2021). Spatial transcriptomics techniques were powerful in resolving the dynamic change within the niches under specific biological context, and efforts were made to increase the resolution and integrated the scRNA seq with spatial transcriptomes.

In most cases, scRNA-seq was employed in vivo experiment but its application in vitro also helps people to resolve complex kidney pathogenic mechanism, especially when studying cells underwent asynchronous differentiation or continuous transition. Kidney organoids which were generated from human 
TABLE 2 | Summary of scRNA-seq in kidney diseases.

\begin{tabular}{|c|c|c|c|c|c|c|c|}
\hline $\begin{array}{l}\text { Author } \\
\text { information }\end{array}$ & Arazi et al., 2019 & Der et al., 2019 & Fu et al., 2019 & Wilson et al., 2019 & Zheng et al., 2020 & Tang et al., 2021 & Krebs et al., 2020 \\
\hline Disease type & $\mathrm{LN}$ & LN & DKD & $\mathrm{DKD}$ & $\lg A N$ & $\lg A N$ & ANCA-GN \\
\hline $\begin{array}{l}\text { scRNA-seq } \\
\text { method }\end{array}$ & $\begin{array}{l}\text { Modified } \\
\text { CEL-Seq2 }\end{array}$ & Fluidigm C1 & Fluidigm C1 & $10 \times$ chromium & $\begin{array}{l}\text { Modified } \\
\text { STRT-seq }\end{array}$ & Singleron Matrix & $\begin{array}{l}10 \times \text { chromium } \\
\text { CITE-seq }\end{array}$ \\
\hline Species & Human & Human & Mouse & Human & Human & Human & Human and mouse \\
\hline Tissue origin & $\begin{array}{l}\text { Kidney biopsy, } \\
\text { blood }\end{array}$ & $\begin{array}{l}\text { Kidney and skin } \\
\text { biopsy, blood }\end{array}$ & Kidney tissue & $\begin{array}{l}\text { Kidney biopsy, } \\
\text { blood }\end{array}$ & $\begin{array}{l}\text { Kidney biopsy, } \\
\text { blood }\end{array}$ & $\begin{array}{l}\text { Kidney biopsy, } \\
\text { blood }\end{array}$ & $\begin{array}{l}\text { Kidney biopsy, } \\
\text { blood }\end{array}$ \\
\hline \multirow[t]{2}{*}{$\begin{array}{l}\text { Human sample } \\
\text { number }\end{array}$} & 10 control & 3 control & 3 control & 3 non-diabetic & 5 control & $\begin{array}{l}1 \text { control } \\
\text { (GSE131685) }\end{array}$ & 3 control \\
\hline & 24 LN & $\begin{array}{l}21 \text { LN kidney } \\
\text { biopsy, } 17 \text { skin } \\
\text { biopsy }\end{array}$ & 3 STZ-diabetes & 3 Diabetes & $5 \lg A N$ & $4 \lg A N$ & 3 ANCA-GN \\
\hline $\begin{array}{l}\text { Cell number for } \\
\text { analysis }\end{array}$ & 2,736 & 4,019 & 829 & 23,980 & 8,880 & 20,570 & 5,905 \\
\hline $\begin{array}{l}\text { Features of the } \\
\text { study }\end{array}$ & $\begin{array}{l}21 \text { leukocyte } \\
\text { clusters; local } \\
\text { activation of B cells; } \\
\text { renal differentiation } \\
\text { of monocytes; type } \\
1 \text { interferon } \\
\text { response genes in } \\
\text { most cells; broad } \\
\text { expression of } \\
\text { CXCR4 and } \\
\text { CX3CR1 }\end{array}$ & $\begin{array}{l}\text { Enriched type I } \\
\text { interferon response } \\
\text { genes; association } \\
\text { of high IFN } \\
\text { response and } \\
\text { fibrotic genes in } \\
\text { tubular cells with } \\
\text { non-responders }\end{array}$ & $\begin{array}{l}\text { Increased number } \\
\text { of immune cells in } \\
\text { DKD glomeruli; } \\
\text { macrophages are } \\
\text { major immune cell } \\
\text { type; higher } \\
\text { number of M1 } \\
\text { macrophages than } \\
\text { M2 }\end{array}$ & $\begin{array}{l}4 \text { clusters of } \\
\text { immune cells, } \\
\text { including T, B, } \\
\text { monocytes, and } \\
\text { plasma cells; } \\
\text { increased number } \\
\text { of leukocytes; } \\
\text { increased } \\
\text { expression of } \\
\text { TNFRSF21 in } \\
\text { monocytes }\end{array}$ & $\begin{array}{l}\text { Increased } \\
\text { interactions } \\
\text { between mesangial } \\
\text { cells, } \\
\text { macrophages, and } \\
\text { T cells; increased } \\
\text { Notch, glycolysis, } \\
\text { fatty acid, and } \\
\text { amino-acid } \\
\text { metabolism genes } \\
\text { in macrophages; } \\
\text { increased } \\
\text { expression of CCL2 } \\
\text { and CX3CR1 in } \\
\text { macrophages }\end{array}$ & $\begin{array}{l}\text { Detected } \\
\text { macrophages, } \\
\text { monocytes, and } \\
\text { DCs but not T cells } \\
\text { in IgAN kidney; } \\
\text { decreased } \\
\text { expression of } \\
\text { GPX3, FAM49B, } \\
\text { and FCGBP in } \\
\text { macrophages; } \\
\text { increased } \\
\text { expression of CCL2 } \\
\text { and CXCL1; } \\
\text { increased } \\
\text { expression of } \\
\text { Notch, FGF2 and } \\
\text { PDGFD in } \\
\text { mesangial cells }\end{array}$ & $\begin{array}{l}12 \text { clusters of renal } \\
\mathrm{T} \text { cells; } \\
\mathrm{CCR}^{\text {high }}{ }^{\mathrm{CCR} 7-} \\
\mathrm{CD}^{+}{ }^{+} \mathrm{CD}^{+}{ }^{+} \mathrm{T}_{\mathrm{RM}} \\
\text { cells display Th17 } \\
\text { signature in } \\
\text { ANCA-GN; } \\
\text { pathogen infection } \\
\text { induces } \mathrm{T}_{\mathrm{RM}} 17 \\
\text { cells in kidney; } \\
\text { increased level of } \\
\text { IL-17A from } \mathrm{T}_{\mathrm{RM}} 17 \\
\text { cells }\end{array}$ \\
\hline
\end{tabular}

pluripotent stem cells had self-organizing 3D structure and mimicked the functions of human kidney. Kidney organoids emerged as human-based models to study multiple kidney cells as a whole in vitro and serve to biomarker discovery and drug invention (Bonventre, 2018). By performing scRNA-seq of kidney organoids, Digby et al. (2020) found that kidney organoid demonstrated phenotype of acute kidney injury (AKI) with higher expression of KIM1 and increased cell damage. The main injured cell types of cisplatin was change as concentration altered with interstitial cells at high dose $(50 \mu \mathrm{M})$ and proximal tubule cell at low repeated dose. Their study validates the use of kidney organoids to model AKI in vitro and provided a suitable stimulation protocol to study AKI. Macrophagemyofibroblast transition (MMT) is a newly discovered process and promote kidney fibrosis in a TGF- $\beta$ /Smad3-dependent pattern (Meng et al., 2016; Wang et al., 2016). By performing scRNA-seq to study sorted TGF- $\beta 1$-treated Smad3 ${ }^{+/+}$and Smad $3^{-/}$bone marrow-derived macrophages (BMDMs), Tang et al. (2018) uncovered that the proto-oncogene Src is a direct target gene of Smad3 and serves as a centric hub in the gene regulatory network during MMT. They also found that neural transcription factor Pou4f1 was predicted as the only transcription factor involved in MMT, and later experiments validated that Pou4f1 promoted MMT-mediated fibrosis via a fibrogenic gene network including Fn1, Pdgfrb, Itgb3 et al. (Tang et al., 2020).

\section{GENERATION OF A KIDNEY CELL ATLAS THROUGH SCRNA-SEQ}

Recently, a number of studies have been published using scRNAseq technology in kidney research, from those seeking to discover rare and novel kidney cell types to elucidating cell type-specific contributions to kidney diseases and understanding intracellular communication networks (Table 2). A groundbreaking progress is the generation of healthy kidney cell atlas, which can serve as a reference transcriptomic map for the future studies (Park et al., 2018). Park et al. (2018) applied scRNA-seq to healthy mouse kidneys and provided a molecular definition of kidney cells. They found five clusters of immune cells in the kidney including macrophages, neutrophils, natural killer cells, B lymphocytes and $\mathrm{T}$ lymphocytes. Among them, $\mathrm{T}$ lymphocytes had the largest number. They also discovered a novel collecting duct cell population, which expresses both intercalated and principal cell markers. They found that a transition between cells of this subpopulation. When compared with the transcriptional profiles of kidney cells from a mouse fibrosis model, these novel cells 
discovered by Park et al. (2018) exhibited a shift in the transition balance toward principal cells. Since intercalated cells play critical roles in proton secretion, a decreased number of intercalated cells may lead to metabolic acidosis in CKD patients.

To define the heterogeneity among epithelial, myeloid, and lymphoid cells, Stewart et al. (2019) performed scRNA-seq using healthy fetal and adult kidney samples. They discovered that several immune cell populations in fetal kidneys appear at the different time points. Certain types of DCs and macrophages were found to be present at the earliest development stage, while NK cells, T cells, and monocytes appeared at 9 weeks of gestation, and B cells were found to present at 12 weeks. These data reveal the temporal development of immune cells at single-cell resolution in human fetal kidney. Using mature kidney samples, this group identified a higher number of immune cells, including resident macrophages, pDCs, neutrophils, mast cells, T, B, NK, and NKT cells, compared to that of fetal kidney samples. In the lymphoid compartment of fetal kidney, $\mathrm{B}$ cells did not express class-switching genes, and CD8 $+\mathrm{T}$ cells expressed the low effector gene GZMH, while in healthy mature kidneys, B cell clusters expressed IgM, IgG, and IgA, and polarization of $\mathrm{CD} 4+\mathrm{T}$ cells was not found through an analysis of cytokine and transcription factor expression. Within the NK clusters, there were cells expressing both $\gamma$ - and $\delta$-T cell receptors as well as markers of mucosalassociated invariant $\mathrm{T}$ (MAIT) cells. They also demonstrated that CD8 + T and NK cells in fetal kidneys show decreased enrichment with genes involved in "T cell receptor signaling" and "NK cell-mediated immunity," respectively, compared to those cells in mature kidneys. Interestingly, Stewart et al. (2019) also discovered that the transcriptome profiles of macrophages in both fetal and mature kidneys resembled those of antiinflammatory M2 macrophages. Compared with the monocytes in fetal kidney, monocyte-derived macrophages displayed higher levels of phagocytosis genes and defense genes to bacteria in mature kidney. Taken together, these studies provide a novel immune cell landscape in mouse and human kidneys, which can be used as a reference dataset and will facilitate the future study of pathogenic mechanisms.

\section{SCRNA-SEQ IN LUPUS NEPHRITIS}

Lupus nephritis (LN) is caused by systemic lupus erythematosus (SLE), an autoimmune disorder in which the immune system targets the body's own cells (Davidson and Aranow, 2010; Tsokos, 2011). LN occurs when lupus autoantibodies attack the kidneys, which leads to hematuria, proteinuria, impaired kidney function, and even kidney failure. Considerable evidence from pathological and bulk RNA-seq analyses of LN kidney samples suggests that the infiltration of lymphocytes is closely associated with reduced kidney function as well as a poor patient prognosis. One early study, in which scRNA-seq was performed with kidney and skin samples from patients with LN and with skin samples from healthy donors, generated data on 899 cells (Der et al., 2017). This study demonstrated a correlation between type I interferon signaling in renal tubular cells and skin keratinocytes in patients with active lupus nephritis, suggesting the potential of evaluating LN activity with skin biopsy samples. Unfortunately, the immune cells identified in this study were very limited due to the small number of sequenced cells, although some T cells and myeloid cells were observed in patients with LN.

Later, using strategies to enrich immune cells before sequencing, two studies reported detailed immune cell landscapes of the kidneys in LN patients (Arazi et al., 2019; Der et al., 2019). Both studies suggested that an abundant number of immune cells are present in the kidneys of patients with LN, including inflammatory and phagocytic macrophages, DCs, NK cells, B cells, and a group of memory $\mathrm{T}$ cells. The infiltrating myeloid and lymphoid cells detected by scRNA-seq were confirmed using immunohistochemical and immunofluorescent methods. Interestingly, a subset consisting of B and plasma cells, which are the major sources of autoantibodies, was found to express type I interferon signature genes in LN kidneys, implying that these cells play important roles in LN pathogenesis. In normal kidney tissue, there are two predominant immune cell populations: a population of myeloid cells that differs from the blood myeloid cell population and a population of effector memory CD4 $+\mathrm{T}$ cells. Notably, with scRNA-seq, no B cells were found in healthy kidneys, which was confirmed by the flow cytometry assay. These results identify the cell populations that contribute to immunemediated kidney injury in lupus nephritis and provide novel insights into B cells and plasma cells, showing that they may contribute to LN pathogenesis through clonal expansion at the site of injury; however, further studies are needed to investigate the detailed mechanism.

In addition, Arazi et al. (2019) demonstrated the possibility of performing scRNA-seq with immune cells in urine samples, which provides a non-invasive way to study immune cells in kidneys. Previously, Park et al. (2018) mapped the diseaseassociated genes, which were identified from the GWAS and other genetic studies, to their scRNA-seq dataset of mouse kidneys and generated a cell type-specific expression profile of these disease-associated genes. Similar to this approach, the Accelerating Medicines Partnership Network integrated risk genes from GWAS of SLE patients with the scRNA-seq data generated from patients with LN (Der et al., 2017; Arazi et al., 2019). Therefore, this approach, the integration of scRNAseq data and genetic data, provides additional information to understand the cell type-specific contribution to kidney disease pathogenesis.

\section{SCRNA-SEQ IN DIABETIC KIDNEY DISEASE}

Diabetic kidney disease (DKD) is one of the most common microvascular complications of diabetic mellitus and a leading cause of end-stage renal disease (ESRD) worldwide (Reidy et al., 2014; Thomas et al., 2015). Although numerous studies have indicated that immune cells play essential roles in DKD pathogenesis, the detailed mechanism remains unelucidated (Wada and Makino, 2016; Flyvbjerg, 2017; Tang and Yiu, 2020). In a recent study, scRNA-seq was performed using DKD and 
normal kidney tissues, and showed that several types of immune cells are increased in the glomeruli of diabetic mice (Fu et al., 2019). The major immune cells detected were macrophages with highly expressed C1qa, Cd74, and Adgre1. Macrophages have been previously classified into two subtypes: M1 and M2 macrophages, which are associated with tissue damage and repair, respectively. Studies have demonstrated that the increased ratio of M1/M2 macrophages in kidneys strongly correlates with the urine albumin level and renal fibrosis in DKD (You et al., 2013). Fu et al. (2019) investigated macrophage clusters in DKD kidney samples based on 57 and 33 marker genes of M1 and M2, respectively. As expected, they found a higher number of M1 macrophages than M2 macrophages in the DKD samples. This result is consistent with previous studies showing that inflammatory macrophages are the major immune cells in the glomeruli of DKD. In addition, only a small number of other immune cells, such as neutrophils and B cells, were observed in the DKD kidney samples. Thus, this study suggests that dysregulation of the M1/M2 macrophage balance may contribute to tissue injury in DKD kidneys.

In contrast to Fu et al. (2019) study, Wilson et al. (2019) performed snRNA-seq and observed an approximate 7 fold increase in leukocyte number in diabetic patients; however, they failed to detect a significant number of resident macrophages in the diabetic samples. This discrepancy between two studies may be due to a limited sequencing cell number or different sequencing methods. Intriguingly, Wilson et al. (2019) found that infiltrating monocytes expressed the IFN gamma (IFNGR1 and IFNGR2) downstream signaling genes, such as HLA class II genes (HLA-DRB1, HLA-DRB5, HLA-DQA1), and TNFRSF1B, which are implicated as biomarkers for DKD (Benjafield et al., 2001; Robson et al., 2018; Xu et al., 2018). When comparing diabetic samples with 2 public datasets of PBMCs, Wilson et al. (2019) observed increased expression of TNFRSF21, one of the kidney risk inflammatory signature (KRIS) genes, in infiltrating CD14 + monocyte populations in diabetic samples. Interestingly, TNFRSF21 is also one of the few KRIS urinary markers that was correlated with enhanced urinary excretion and ESRD. Taken together, these studies indicate that macrophages/monocytes play important roles in DKD pathogenesis.

Using the snRNA-seq dataset generated by Wilson et al. (2019), Wei et al. (2021) found that DKD samples with high interstitial fibrosis and tubular atrophy displayed a higher cell number of B cells, suggesting that B cells may also play roles in DKD. Although a number of studies have confirmed the contribution of B cells in the pathogenesis of $\mathrm{LN}$, recurrent focal segmental glomerulosclerosis, and membranous nephropathy (Fornoni et al., 2011; Gregersen and Jayne, 2012; Fervenza et al., 2019), the roles of B cells in DKD remains unclear. Studies have shown that the peripheral $\mathrm{CD}^{+} 9^{+} \mathrm{CD}_{3}{ }^{+} \mathrm{B}$ cells was increased in diabetic patients (Smith et al., 2017). Notably, the number of $\mathrm{CD} 19^{+} \mathrm{CD}^{+} 8^{+} \mathrm{B}$ cells was found to be closely correlated with $24 \mathrm{~h}$ proteinuria level and was reduced after treatment. Taken together, these studies provide a landscape of immune cells in DKD and potential targets for DKD diagnosis and treatment.

\section{SCRNA-SEQ IN IgA NEPHROPATHY}

IgA nephropathy (IgAN) is a common primary glomerulonephritis worldwide. Although this disease was initially described five decades ago, there are no specific or effective treatments to date. Approximately one-third of IgAN patients will progress to ESRD within 30 years after biopsybased diagnosis (Roberts, 2014; Lai et al., 2016; Rodrigues et al., 2017). Recently, a "four-hit" model was proposed to explain the pathogenesis of IgAN: Unknown upstream factors cause the synthesis of galactose-deficient (gd)-IgA1 and the formation of gd-IgA-IgG immune complexes; deposition of immune complexes causes mesangial cell proliferation and secretion of inflammatory molecules and extracellular matrix (ECM) components; these molecules eventually lead to local activation of the immune system, glomerular sclerosis, mesangial expansion, and interstitial fibrosis (Lai, 2012; Wyatt and Julian, 2013; Roberts, 2014; Soares and Roberts, 2018). However, studies have shown that deposition of gd-IgA1-IgG immune complexes alone in the mesangium is not sufficient to induce severe kidney injury, suggesting that the accompanying inflammation contributes to IgAN pathogenesis, although the detailed mechanisms remain unclear.

To study circulating and resident immune cells, as well as other kidney cells, in IgAN, Zheng et al. (2020) applied a modified STRT-seq method and generated a single-cell transcriptome atlas of mesangial cells, epithelial cells, and circulating and resident immune cells. They applied the stepwise isolation method and captured major cell types in kidney cortex, generating a dataset with more than 3,000 genes and 30,000 transcripts per cell. Interestingly, they uncovered that mesangial cell of IgAN patients expressed higher levels of JCHAIN, a gene related to the dimerization and transportation of IgA molecules, which is predominately expressed in B cells. The increased expression level of this gene in mesangial cells may explain the mesangium-specific deposition of IgA immune complexes. This group also validated this result at the protein level; however, the detailed mechanism remains to be further investigated. In addition, Zheng et al. (2020) found that mesangial cells of IgAN patients expressed several inflammatory and ECM genes. In normal adult kidneys, mesangial cells are thought to clear immunoglobulins and ECM components; therefore, mesangial cell proliferation and ECM accumulation are tightly regulated (Mene et al., 1989). Under IgAN conditions, however, mesangial cells may have impaired functions in production and clearance of specific cellular components, leading to progressive kidney injury.

In another scRNA-seq study, Tang et al. (2021) discovered that mesangial cells of IgAN patients displayed the increased expression of MALAT1, GADD45B, SOX4, and EDIL3, which are also related to cell proliferation and matrix accumulation. The JCHAIN gene discovered by Zheng et al. (2020), however, did not appear in Tang et al. (2021) analysis results. This discrepancy might be due to the different sample dissociation methods (stepwise isolation vs. the GEXSCOPE tissue dissociation method) or the different sequencing platforms (modified STRT-seq vs. Singleron Biotechnologies 
platform). Nonetheless, both studies showed that mesangial cell proliferation and matrix accumulation play an essential role in IgAN pathogenesis.

It has been reported that the infiltration and accumulation of immune cells, especially macrophages/monocytes, in IgAN kidney tissue are associated with proteinuria and kidney damage in IgAN. However, the detailed mechanism of macrophage/monocyte recruitment remains unclear. Both studies discovered increased numbers of macrophages, monocytes, and DCs in the kidney of IgAN patients. Zheng et al. (2020) revealed that PLGRKT and CCL2, two cytokines that can recruit macrophages/monocytes, were highly expressed in mesangial cells of IgAN patients. Tang et al. (2021) found that three genes GPX3, FAM49B, and FCGBP, which are related to the mitochondrial function, ROS production, and EMT, respectively, were decreased in macrophages of IgAN. Taken together, these results provide new evidence showing how macrophages/monocytes contribute to IgAN pathogenesis. Furthermore, Zheng et al. (2020) found that the expression of effector $\mathrm{T}$ cell marker genes and cytotoxicity genes was significantly reduced, while the expression of $\mathrm{T}$ cell exhaustion genes was upregulated in CD8 $+\mathrm{T}$ cells of IgAN patients. These findings suggest a close association between CD8 $+\mathrm{T}$ cell dysfunction and IgAN pathogenesis; however, the detailed mechanism needs to be further investigated.

\section{SCRNA-SEQ IN ANTI-NEUTROPHIL CYTOPLASMIC ANTIBODY-ASSOCIATED GLOMERULONEPHRITIS}

Anti-neutrophil cytoplasmic antibody (ANCA)-associated glomerulonephritis (ANCA-GN) is characterized by an autoimmune response to ANCAs and distinct glomerular lesions (Berden et al., 2010). Previous studies have indicated that distinct HLA class II haplotypes and $\mathrm{CD} 4^{+} \mathrm{T}$ cells are strongly associated with ANCA-GN (Spencer et al., 1992; Chanouzas et al., 2015). Substantial infiltrating $\mathrm{CD}^{+} \mathrm{T}$ cells was found in kidney biopsy samples of patients with crescentic GN. In addition, $\mathrm{CD}^{+} \mathrm{T}$ cells react to self-antigens in the active disease stage (Krebs et al., 2017). Experiments with rodent crescentic GN models suggested that CD4 ${ }^{+}$T cells, particularly Th17 cells, promote GN disease progression through the production of related cytokines, such as IL-17A, IL-17F, and IFN- $\gamma$. However, the contribution of other $\mathrm{T}$ cells to ANCA-GN pathogenesis remains unclear.

Therefore, Krebs et al. (2020) investigated T cells in ANCAGN kidneys using scRNA-seq. Compared with healthy kidney samples, the authors found that samples of patients with ANCAGN displayed a significantly increased number of $\mathrm{CD} 4^{+}$tissue resident memory $\mathrm{T}\left(\mathrm{T}_{\mathrm{RM}}\right)$ cells. In addition, they discovered that a higher number of kidney resident $\mathrm{CD} 9^{+}$cells is negatively associated with kidney function in patients with active ANCAGN. Interestingly, major subsets of $\mathrm{CD}^{+} \mathrm{CD}^{+} 9^{+} \mathrm{T}_{\mathrm{RM}}$ cells exhibit transcriptomic profiles similar to that of Th1 or Th17 cells. They also displayed increased expression level of genes involved in cell proliferation, activation, and cytokine signaling. Therefore, $\mathrm{CD}^{+} \mathrm{T}_{\mathrm{RM}}$ cells induced by pathogens may play an important role in aggravating ANCA-GN, although the detailed mechanism remains to be elucidated.

\section{FUTURE PROSPECT}

scRNA-seq methods have broadly expand our knowledge of kidney immunity and become more and more powerful and indispensable tools to study kidney diseases nowadays. Using scRNA-seq, people could detect gene expression alterations of specific cell clusters and distinguish universal and unique regulation pattern. scRNA-seq technologies not only help people to uncover mechanism under specific pathology process, but also offer useful information in the disease diagnosis. The diagnosis of many kidney diseases rely largely on invasive biopsy and histologic report. As mentioned before, Arazi et al. (2019) showed that the scRNA-seq profile of immune cells in urine samples was highly correlated. It is possible that scRNA-seq could be considered as a substitution of kidney biopsy as it becomes more economic in the future.

\section{CONCLUSION}

scRNA-seq data generated in different laboratories on the basis of many kinds of human tissues will contribute to the Human Cell Atlas, an international database with a comprehensive and systematic reference map of human cells in health and disease. Eventually, this database will facilitate research by providing a reference transcriptome atlas at single-cell resolution. Currently, single-cell technology is increasing our understanding of kidney immunology at a revolutionary speed. It helps researchers understand cell heterogeneity, gene regulation, and cell-cell communication in kidney diseases, which will benefit disease diagnosis, therapeutic target identification, and off-target effect improvement. The studies discussed here applied singlecell technology to a wide range of immune-related kidney diseases using renal biopsy samples, cells in urine, and/or blood samples. scRNA-seq has led to the discovery of novel immune cell populations, gene regulation, and signaling pathways in immune-related kidney diseases. These findings will improve our understanding of kidney immunology in healthy individuals and patients with disease.

\section{AUTHOR CONTRIBUTIONS}

HZ, XY, SL, and YZ wrote the manuscript. All authors contributed to the article and approved the submitted version.

\section{FUNDING}

This work was funded by the National Natural Science Foundation of China (NSFC, Fund Nos. 81800635 and 81970632). 


\section{REFERENCES}

Arazi, A., Rao, D. A., Berthier, C. C., Davidson, A., Liu, Y., Hoover, P. J., et al. (2019). The immune cell landscape in kidneys of patients with lupus nephritis. Nat. Immunol. 20, 902-914. doi: 10.1038/s41590-019-0398-x

Benjafield, A. V., Glenn, C. L., Wang, X. L., Colagiuri, S., and Morris, B. J. (2001). TNFRSF1B in genetic predisposition to clinical neuropathy and effect on HDL cholesterol and glycosylated hemoglobin in type 2 diabetes. Diabetes Care 24, 753-757. doi: 10.2337/diacare.24.4.753

Berden, A. E., Ferrario, F., Hagen, E. C., Jayne, D. R., Jennette, J. C., Joh, K., et al. (2010). Histopathologic classification of ANCA-associated glomerulonephritis. J. Am. Soc. Nephrol. 21, 1628-1636. doi: 10.1681/ASN.2010050477

Betjes, M. G. (2013). Immune cell dysfunction and inflammation in end-stage renal disease. Nat. Rev. Nephrol. 9, 255-265. doi: 10.1038/nrneph.2013.44

Bonventre, J. V. (2018). Kidney organoids-a new tool for kidney therapeutic development. Kidney Int. 94, 1040-1042. doi: 10.1016/j.kint.2018.07.029

Cao, Q., Zheng, D., Wang, Y. P., and Harris, D. C. (2011). Macrophages and dendritic cells for treating kidney disease. Nephron. Exp. Nephrol. 117, e47-e52. doi: 10.1159/000320595

Chanouzas, D., Dyall, L., Dale, J., Moss, P., Morgan, M., and Harper, L. (2015). CD4+CD28- T-cell expansions in ANCA-associated vasculitis and association with arterial stiffness: baseline data from a randomised controlled trial. Lancet 385(Suppl. 1):S30. doi: 10.1016/S0140-6736(15)60345-2

Davidson, A., and Aranow, C. (2010). Lupus nephritis: lessons from murine models. Nat. Rev. Rheumatol. 6, 13-20. doi: 10.1038/nrrheum.2009.240

Der, E., Ranabothu, S., Suryawanshi, H., Akat, K. M., Clancy, R., Morozov, P., et al. (2017). Single cell RNA sequencing to dissect the molecular heterogeneity in lupus nephritis. JCI Insight 2017:2. doi: 10.1172/jci.insight.93009

Der, E., Suryawanshi, H., Morozov, P., Kustagi, M., Goilav, B., Ranabothu, S., et al. (2019). Tubular cell and keratinocyte single-cell transcriptomics applied to lupus nephritis reveal type I IFN and fibrosis relevant pathways. Nat. Immunol. 20, 915-927. doi: 10.1038/s41590-019-0386-1

Digby, J. L. M., Vanichapol, T., Przepiorski, A., Davidson, A. J., and Sander, V. (2020). Evaluation of cisplatin-induced injury in human kidney organoids. Am. J. Physiol. Renal. Physiol. 318, F971-F978. doi: 10.1152/ajprenal.00597.2019

Donnan, M. D., Kenig-Kozlovsky, Y., and Quaggin, S. E. (2021). The lymphatics in kidney health and disease. Nat. Rev. Nephrol. 17, 655-675. doi: 10.1038/s41581021-00438-y

Eardley, K. S., Kubal, C., Zehnder, D., Quinkler, M., Lepenies, J., Savage, C. O., et al. (2008). The role of capillary density, macrophage infiltration and interstitial scarring in the pathogenesis of human chronic kidney disease. Kidney Int 74, 495-504. doi: 10.1038/ki.2008.183

Fervenza, F. C., Appel, G. B., Barbour, S. J., Rovin, B. H., Lafayette, R. A., Aslam, N., et al. (2019). Rituximab or Cyclosporine in the Treatment of Membranous Nephropathy. N. Engl. J. Med. 381, 36-46. doi: 10.1056/NEJMoa1814427

Flyvbjerg, A. (2017). The role of the complement system in diabetic nephropathy. Nat. Rev. Nephrol. 13, 311-318. doi: 10.1038/nrneph.2017.31

Fornoni, A., Sageshima, J., Wei, C., Merscher-Gomez, S., Aguillon-Prada, R., Jauregui, A. N., et al. (2011). Rituximab targets podocytes in recurrent focal segmental glomerulosclerosis. Sci. Transl. Med. 3:85ra46. doi: 10.1126/ scitranslmed.3002231

Fu, J., Akat, K. M., Sun, Z., Zhang, W., Schlondorff, D., Liu, Z., et al. (2019). Single-Cell RNA Profiling of Glomerular Cells Shows Dynamic Changes in Experimental Diabetic Kidney Disease. J. Am. Soc. Nephrol. 30, 533-545. doi: 10.1681/asn.2018090896

Gierahn, T. M., Wadsworth, M. H. II, Hughes, T. K., Bryson, B. D., Butler, A., Satija, R., et al. (2017). Seq-Well: portable, low-cost RNA sequencing of single cells at high throughput. Nat. Methods 14, 395-398. doi: 10.1038/nmeth. 4179

Gregersen, J. W., and Jayne, D. R. (2012). B-cell depletion in the treatment of lupus nephritis. Nat. Rev. Nephrol. 8, 505-514. doi: 10.1038/nrneph.2012.141

Habib, N., Avraham-Davidi, I., Basu, A., Burks, T., Shekhar, K., Hofree, M., et al. (2017). Massively parallel single-nucleus RNA-seq with DroNc-seq. Nat. Methods 14, 955-958. doi: 10.1038/nmeth.4407

Isbel, N. M., Nikolic-Paterson, D. J., Hill, P. A., Dowling, J., and Atkins, R. C. (2001). Local macrophage proliferation correlates with increased renal M-CSF expression in human glomerulonephritis. Nephrol. Dial. Transplant 16, 16381647. doi: $10.1093 / \mathrm{ndt} / 16.8 .1638$
Islam, S., Kjallquist, U., Moliner, A., Zajac, P., Fan, J. B., Lonnerberg, P., et al. (2011). Characterization of the single-cell transcriptional landscape by highly multiplex RNA-seq. Genome Res. 21, 1160-1167. doi: 10.1101/gr.110882.110

Krebs, C. F., Reimers, D., Zhao, Y., Paust, H. J., Bartsch, P., Nunez, S., et al. (2020). Pathogen-induced tissue-resident memory TH17 (TRM17) cells amplify autoimmune kidney disease. Sci. Immunol. 2020:5. doi: 10.1126/sciimmunol. aba4163

Krebs, C. F., Schmidt, T., Riedel, J. H., and Panzer, U. (2017). T helper type 17 cells in immune-mediated glomerular disease. Nat. Rev. Nephrol. 13, 647-659. doi: 10.1038/nrneph.2017.112

Krishnaswami, S. R., Grindberg, R. V., Novotny, M., Venepally, P., Lacar, B., Bhutani, K., et al. (2016). Using single nuclei for RNA-seq to capture the transcriptome of postmortem neurons. Nat. Protoc. 11, 499-524. doi: 10.1038/ nprot.2016.015

Kurts, C., Ginhoux, F., and Panzer, U. (2020). Kidney dendritic cells: fundamental biology and functional roles in health and disease. Nat. Rev. Nephrol. 16, 391-407. doi: 10.1038/s41581-020-0272-y

Kurts, C., Panzer, U., Anders, H. J., and Rees, A. J. (2013). The immune system and kidney disease: basic concepts and clinical implications. Nat. Rev. Immunol. 13, 738-753. doi: 10.1038/nri3523

Lacar, B., Linker, S. B., Jaeger, B. N., Krishnaswami, S. R., Barron, J. J., Kelder, M. J. E., et al. (2016). Nuclear RNA-seq of single neurons reveals molecular signatures of activation. Nat. Commun. 7:11022. doi: 10.1038/ncomms12020

Lai, K. N. (2012). Pathogenesis of IgA nephropathy. Nat. Rev. Nephrol. 8, 275-283. doi: 10.1038/nrneph.2012.58

Lai, K. N., Tang, S. C., Schena, F. P., Novak, J., Tomino, Y., Fogo, A. B., et al. (2016). IgA nephropathy. Nat. Rev. Dis. Primers 2:16001. doi: 10.1038/nrdp.2016.1

Longo, S. K., Guo, M. G., Ji, A. L., and Khavari, P. A. (2021). Integrating single-cell and spatial transcriptomics to elucidate intercellular tissue dynamics. Nat. Rev. Genet. 22, 627-644. doi: 10.1038/s41576-021-00370-8

Macosko, E. Z., Basu, A., Satija, R., Nemesh, J., Shekhar, K., Goldman, M., et al. (2015). Highly Parallel Genome-wide Expression Profiling of Individual Cells Using Nanoliter Droplets. Cell 161, 1202-1214. doi: 10.1016/j.cell.2015.05.002

Mene, P., Simonson, M. S., and Dunn, M. J. (1989). Physiology of the mesangial cell. Physiol. Rev. 69, 1347-1424. doi: 10.1152/physrev.1989.69.4.1347

Meng, X. M., Wang, S., Huang, X. R., Yang, C., Xiao, J., Zhang, Y., et al. (2016). Inflammatory macrophages can transdifferentiate into myofibroblasts during renal fibrosis. Cell Death Dis. 7:e2495. doi: 10.1038/cddis.2016.402

Papalexi, E., and Satija, R. (2018). Single-cell RNA sequencing to explore immune cell heterogeneity. Nat. Rev. Immunol. 18, 35-45. doi: 10.1038/nri.2017.76

Park, J., Shrestha, R., Qiu, C., Kondo, A., Huang, S., Werth, M., et al. (2018). Single-cell transcriptomics of the mouse kidney reveals potential cellular targets of kidney disease. Science 360, 758-763. doi: 10.1126/science. aar2131

Park, J. G., Lee, C. R., Kim, M. G., Kim, G., Shin, H. M., Jeon, Y. H., et al. (2020). Kidney residency of VISTA-positive macrophages accelerates repair from ischemic injury. Kidney Int. 97, 980-994. doi: 10.1016/j.kint.2019. 11.025

Puranik, A. S., Leaf, I. A., Jensen, M. A., Hedayat, A. F., Saad, A., Kim, K. W., et al. (2018). Kidney-resident macrophages promote a proangiogenic environment in the normal and chronically ischemic mouse kidney. Sci. Rep. 8:13948. doi: 10.1038/s41598-018-31887-4

Ramskold, D., Luo, S., Wang, Y. C., Li, R., Deng, Q., Faridani, O. R., et al. (2012). Full-length mRNA-Seq from single-cell levels of RNA and individual circulating tumor cells. Nat. Biotechnol. 30, 777-782. doi: 10.1038/nbt.2282

Reidy, K., Kang, H. M., Hostetter, T., and Susztak, K. (2014). Molecular mechanisms of diabetic kidney disease. J. Clin. Invest. 124, 2333-2340. doi: 10.1172/JCI72271

Roberts, I. S. (2014). Pathology of IgA nephropathy. Nat. Rev. Nephrol. 10, 445-454. doi: 10.1038/nrneph.2014.92

Robson, K. J., Ooi, J. D., Holdsworth, S. R., Rossjohn, J., and Kitching, A. R. (2018). HLA and kidney disease: from associations to mechanisms. Nat. Rev. Nephrol. 14, 636-655. doi: 10.1038/s41581-018-0057-8

Rodrigues, J. C., Haas, M., and Reich, H. N. (2017). IgA Nephropathy. Clin. J. Am. Soc. Nephrol. 12, 677-686. doi: 10.2215/CJN.07420716

Smith, M. J., Simmons, K. M., and Cambier, J. C. (2017). B cells in type 1 diabetes mellitus and diabetic kidney disease. Nat. Rev. Nephrol. 13, 712-720. doi: 10.1038/nrneph.2017.138 
Soares, M. F. S., and Roberts, I. S. D. (2018). Histologic Classification of IgA Nephropathy: Past, Present, and Future. Semin. Nephrol. 38, 477-484. doi: 10.1016/j.semnephrol.2018.05.017

Spencer, S. J., Burns, A., Gaskin, G., Pusey, C. D., and Rees, A. J. (1992). HLA class II specificities in vasculitis with antibodies to neutrophil cytoplasmic antigens. Kidney Int. 41, 1059-1063. doi: 10.1038/ki.1992.161

Stewart, B. J., Ferdinand, J. R., Young, M. D., Mitchell, T. J., Loudon, K. W., Riding, A. M., et al. (2019). Spatiotemporal immune zonation of the human kidney. Science 365, 1461-1466. doi: 10.1126/science.aat5031

Tang, F., Barbacioru, C., Wang, Y., Nordman, E., Lee, C., Xu, N., et al. (2009). mRNA-Seq whole-transcriptome analysis of a single cell. Nat. Methods 6, 377-382. doi: 10.1038/nmeth.1315

Tang, P. M., Zhang, Y. Y., Xiao, J., Tang, P. C., Chung, J. Y., Li, J., et al. (2020). Neural transcription factor Pou4f1 promotes renal fibrosis via macrophagemyofibroblast transition. Proc. Natl. Acad. Sci. U S A 117, 20741-20752. doi: 10.1073/pnas.1917663117

Tang, P. M., Zhou, S., Li, C. J., Liao, J., Xiao, J., Wang, Q. M., et al. (2018). The proto-oncogene tyrosine protein kinase Src is essential for macrophagemyofibroblast transition during renal scarring. Kidney Int 93, 173-187. doi: 10.1016/j.kint.2017.07.026

Tang, R., Meng, T., Lin, W., Shen, C., Ooi, J. D., Eggenhuizen, P. J., et al. (2021). A Partial Picture of the Single-Cell Transcriptomics of Human IgA Nephropathy. Front. Immunol. 12:645988.

Tang, S. C. W., and Yiu, W. H. (2020). Innate immunity in diabetic kidney disease. Nat. Rev. Nephrol. 16, 206-222. doi: 10.1038/s41581-019-0234-4

Teteris, S. A., Engel, D. R., and Kurts, C. (2011). Homeostatic and pathogenic role of renal dendritic cells. Kidney Int. 80, 139-145. doi: 10.1038/ki.2011.129

Thomas, M. C., Brownlee, M., Susztak, K., Sharma, K., Jandeleit-Dahm, K. A., Zoungas, S., et al. (2015). Diabetic kidney disease. Nat. Rev. Dis. Primers 1:15018. doi: $10.1038 /$ nrdp. 2015.70

Tsokos, G. C. (2011). Systemic lupus erythematosus. N. Engl. J. Med. 365, 21102121. doi: 10.1056/NEJMra1100359

Turner, J. E., Becker, M., Mittrucker, H. W., and Panzer, U. (2018). Tissue-Resident Lymphocytes in the Kidney. J. Am. Soc. Nephrol. 29, 389-399. doi: 10.1681/asn. 2017060599

Wada, J., and Makino, H. (2016). Innate immunity in diabetes and diabetic nephropathy. Nat. Rev. Nephrol. 12, 13-26. doi: 10.1038/nrneph.2015.175

Wagner, A., Regev, A., and Yosef, N. (2016). Revealing the vectors of cellular identity with single-cell genomics. Nat. Biotechnol. 34, 1145-1160. doi: 10.1038/ nbt.3711

Wang, S., Meng, X. M., Ng, Y. Y., Ma, F. Y., Zhou, S., Zhang, Y., et al. (2016). TGF- $\beta / S m a d 3$ signalling regulates the transition of bone marrowderived macrophages into myofibroblasts during tissue fibrosis. Oncotarget 7, 8809-8822. doi: 10.18632/oncotarget.6604
Wei, Y., Gao, X., Li, A., Liang, M., and Jiang, Z. (2021). Single-Nucleus Transcriptomic Analysis Reveals Important Cell Cross-Talk in Diabetic Kidney Disease. Front. Med. 8:657956. doi: 10.3389/fmed.2021.657956

Wilson, P. C., Wu, H., Kirita, Y., Uchimura, K., Ledru, N., Rennke, H. G., et al. (2019). The single-cell transcriptomic landscape of early human diabetic nephropathy. Proc. Natl. Acad. Sci. US A 116, 19619-19625. doi: 10.1073/pnas. 1908706116

Wu, H., Kirita, Y., Donnelly, E. L., and Humphreys, B. D. (2019). Advantages of Single-Nucleus over Single-Cell RNA Sequencing of Adult Kidney: Rare Cell Types and Novel Cell States Revealed in Fibrosis. J. Am. Soc. Nephrol. 30, 23-32. doi: 10.1681/ASN.2018090912

Wyatt, R. J., and Julian, B. A. (2013). IgA nephropathy. N. Engl. J. Med. 368, 2402-2414. doi: 10.1056/NEJMra1206793

Xu, X., Eales, J. M., Akbarov, A., Guo, H., Becker, L., Talavera, D., et al. (2018). Molecular insights into genome-wide association studies of chronic kidney disease-defining traits. Nat. Commun. 9:4800. doi: 10.1038/s41467-01807260-4

Yang, N., Wu, L. L., Nikolic-Paterson, D. J., Ng, Y. Y., Yang, W. C., Mu, W., et al. (1998). Local macrophage and myofibroblast proliferation in progressive renal injury in the rat remnant kidney. Nephrol. Dial. Transplant. 13, 1967-1974. doi: $10.1093 / \mathrm{ndt} / 13.8 .1967$

You, H., Gao, T., Cooper, T. K., Brian Reeves, W., and Awad, A. S. (2013). Macrophages directly mediate diabetic renal injury. Am. J. Physiol. Renal. Physiol. 305, F1719-F1727. doi: 10.1152/ajprenal.00141.2013

Zheng, Y., Lu, P., Deng, Y., Wen, L., Wang, Y., Ma, X., et al. (2020). Single-Cell Transcriptomics Reveal Immune Mechanisms of the Onset and Progression of IgA Nephropathy. Cell Rep. 33:108525. doi: 10.1016/j.celrep.2020.108525xs

Conflict of Interest: The authors declare that the research was conducted in the absence of any commercial or financial relationships that could be construed as a potential conflict of interest.

Publisher's Note: All claims expressed in this article are solely those of the authors and do not necessarily represent those of their affiliated organizations, or those of the publisher, the editors and the reviewers. Any product that may be evaluated in this article, or claim that may be made by its manufacturer, is not guaranteed or endorsed by the publisher.

Copyright (c) 2021 Zeng, Yang, Luo and Zhou. This is an open-access article distributed under the terms of the Creative Commons Attribution License (CC BY). The use, distribution or reproduction in other forums is permitted, provided the original author(s) and the copyright owner(s) are credited and that the original publication in this journal is cited, in accordance with accepted academic practice. No use, distribution or reproduction is permitted which does not comply with these terms. 